\title{
DINÂMICA DA CONCENTRAÇÃO DAS EXPORTAÇÕES BRASILEIRAS DE CELULOSE QUÍMICA (1990 - 2010)
}

\section{DYNAMICS OF CONCENTRATION OF BRAZILIAN EXPORTS OF CHEMICAL PULP (1990 - 2010)}

\author{
Thiago Ramos Costa ${ }^{1}$ Rosalina Zefanias Mahanzule ${ }^{2}$ Giovanna Paiva Aguiar ${ }^{3}$ João Carlos \\ Garzel Leodoro da Silva ${ }^{4}$
}

\begin{abstract}
RESUMO
O presente estudo objetivou verificar a dinâmica da concentração e da desigualdade das exportações brasileiras de celulose química. Foram utilizados dados secundários de valor e volume das exportações brasileiras, no período compreendido entre 1990 e 2010, do qual foram calculados os índices: razão de concentração (CR4 e CR8), Herfindahl-Hirschman (HHI) e Gini. Para o índice de desigualdade de Gini e os índices de concentração CR4 e CR8, os anos 2001, 2002 e 2003, respectivamente, marcaram o fim da queda dos níveis de desigualdade e de concentração. O índice HHI teve comportamento similar, porém, em 2006 registrou-se o valor mais baixo. A partir deste período, os índices apresentaram tendência de crescimento, mas não atingiram os patamares do início do período. De forma geral, os resultados demonstraram a redução das concentrações das exportações, assim como o acréscimo do número de parceiros comerciais. Houve aumento, tanto do valor exportado, como do volume e do preço unitário, no período. Os índices calculados são variáveis associadas à capacidade de competição das indústrias e com base nos resultados indicam que o setor de celulose nacional se tornou mais competitivo ao longo do período.
\end{abstract}

Palavras-chave: índice de concentração; Herfindahl-Hirschman; Gini.

\begin{abstract}
This study aimed to analyze the dynamics of concentration and inequality of Brazilian exports of chemical cellulose. Secondary data of value and quantity of Brazilian exports were used, comprising the period between 1990 and 2010. Using this data, the following indexes have been calculated: concentration ratio (CR4 and CR8), Herfindahl-Hirschman Index (HHI) and Gini. For the Gini index of inequality and the concentration ratios CR4 and CR8, the years 2001, 2002 and 2003, respectively, marked the end of the downfall levels of inequality and concentration. The HHI had a similar behavior, but in 2006 presented the lowest value. Thereafter, the rates tended to increase but did not reach the levels of the beginning of the period. Overall, the results showed a decrease in the export concentration as well as an increase in the number of trading partners. There was also an increase in the amount exported, as well as in the volume and unit price, during the period. The calculated indexes are variables associated with the ability of industry competition and based on the results they indicate that the national pulp became more competitive over time.
\end{abstract}

Keywords: concentration index; Herfindahl-Hirschman; Gini.

1 Engenheiro Florestal, MSc., Escola de Florestas, Universidade Federal do Paraná, Av. Pref. Lothário Meissner, 632, Jardim Botânico, CEP 80210-170, Curitiba (PR), Brasil. thiagoramoscosta@gmail.com

2 Engenheira Florestal, MSc., Investigadoura Socio Econômica, Instituto de Investigação de Mocambique, Av. das FPLM, 2698, Caixa Postal 3658, Maputo, Moçambique. romahanzule@gmail.com

3 Engenheira Florestal, MSc., Serviço Florestal Brasileiro, SCEN Trecho 2, Bloco H, CEP 70818-900, Brasília (DF) Brasil. giovanna.paguiar@gmail.com

4 Engenheiro Florestal, Dr., Professor do Departamento de Engenharia Florestal, Universidade Federal do Paraná, Av. Pref. Lothário Meissner, 632, Jardim Botânico, CEP: 80210-170, Curitiba (PR), Brasil. garzel@ufpr.br 


\section{INTRODUÇ̃̃O}

O setor de base florestal brasileiro tem uma importância significativa na balança comercial. Suas exportações superam as importações, colaborando para o superavit da mesma. Ressalta-se ainda sua importância para o desenvolvimento socioeconômico do país, por meio da geração de empregos diretos e indiretos (ASSOCIAÇÃO BRASILEIRA DE CELULOSE E PAPEL, 2011).

Dentre os principais produtos exportados pelo setor de base florestal brasileiro, a celulose vem se destacando cada vez mais, chegando a representar, em média, mais de $90 \%$ do valor comercializado para o exterior (UNITED NATIONS COMMODITY TRADE STATISTICS DATABASE, 2011). Porém, este fato não garante que esta dinâmica se mantenha no futuro. Assim, pesquisas nas mais diferentes áreas, entre elas os estudos sobre competitividade dos produtos de base florestal são necessários para a tomada de decisões, tanto pelo setor público, como pela iniciativa privada, em todos os níveis da cadeia de valor.

Dentre os instrumentos que apoiam as decisões estratégicas encontra-se a família dos estudos de concentração. Dessa forma, os resultados destes estudos servem como instrumento para apoiar a formulação de estratégias futuras de comercialização e produção de celulose química.

Segundo Noce et al. (2005), um dos principais determinantes estruturais da competição é a análise da concentração, tendo os autores desenvolvido a base teórica para a indústria. Os mesmos autores afirmam que essas análises podem afetar alguns fatores como a economia de escala, o tamanho e o crescimento dos mercados, além das condições de entrada. No mesmo sentido, Kon (1994) argumenta que quando a concentração industrial é elevada pode haver prejuízos à alocação eficiente de recursos.

Deste modo, pretende-se, com este estudo, avaliar a evolução das exportações e a dinâmica das concentrações das exportações brasileiras de celulose química, entre os anos 1990 e 2010, tendo como objetivos específicos: demonstrar os valores e os volumes exportados ao longo do período, identificar os principais parceiros comerciais do Brasil neste mercado e analisar a evolução das concentrações e da desigualdade das exportações brasileiras de celulose química para o mundo.

\section{MATERIAIS E MÉTODOS}

Segundo Caves (1982), a concentração é um elemento da estrutura de mercado importante na determinação do seu comportamento e, consequentemente, na determinação da qualidade da atuação da indústria. Já, Melville, Gurbaxani e Kraemer (2007) dizem que a concentração de toda uma indústria é inversamente proporcional à competitividade da mesma. Estes autores, porém, não consideram que pode existir a opção estratégica de especialização em determinados mercados, podendo tornar a indústria altamente competitiva em um mercado específico.

Por sua vez, Kon (1994) descreve várias medidas para verificar o grau de concentração em indústrias, entre elas: a razão de concentração, o índice de Herfindahl-Hirschman e o coeficiente de desigualdade de Gini, afirmando que as medidas acima listadas são necessárias na avaliação do estágio da competição, permitindo examinar a dinâmica do mercado.

Vários autores realizaram estudos sobre a concentração e a desigualdade de mercados do setor florestal, dentre eles: Santos e Santana (2003), Silva (2003), Noce et al. (2005), Soares et al. (2006), Noce et al. (2007) e Coelho Junior et al. (2010).

Esta pesquisa foi desenvolvida utilizando dados secundários referentes aos volumes e valores de exportação brasileira de celulose química coletados no United Nations Commodity Trade Statistics Database (2011), no período compreendido entre 1990 e 2010. Os índices de concentração e desigualdade foram calculados a partir dos dados de volume de celulose química exportado pelo Brasil.

\section{Razão de concentração (CRK)}

Esta medida é utilizada para indicar a proporção das maiores firmas em relação ao valor total da produção do setor correspondente às $\mathrm{k}$ maiores empresas, considerando que estão ordenadas da seguinte forma: $x 1 \geq x 2 \geq x 3 \geq \ldots \geq x n$ (HOFFMANN, 2006). A razão de concentração com a participação dos principais parceiros é um índice muito importante a se observar. 
É comum utilizar-se na mensuração da concentração as proporções das quatro maiores indústrias (CR4) (HOFFMANN, 2006), mas esse índice pode ser analisado para mais firmas. Pesquisas realizadas por outros autores como Feijó, Carvalho e Rodrigues (2003), Martins, Rocha e Barros (2004), Soares et al. (2006), Carvalho et al. (2009) e Coelho Junior et al. (2010) também utilizaram CR1, CR5, CR8 e CR12.

No presente estudo foi calculada a proporção tanto das quatro maiores nações (CR4), como das oito maiores (CR8) importadoras da celulose química brasileira. A razão de concentração foi calculada com base na Equação 1.

$$
C R_{k}=\sum_{i=1}^{k} y i
$$

Em que: $\mathrm{CR}_{\mathrm{k}}=$ relação de concentração das $\mathrm{k}$ maiores nações; $\mathrm{Pi}$ = participação percentual da empresa i no mercado; $\mathrm{k}=$ número de nações

Medeiros e Ostroski (2006), citando Medeiros e Reis (1999), identificaram seis níveis de mercados com base nos índices CR4 e CR8 Para o CR4 foram atribuídos os intervalos dos valores obtidos nos seguintes níveis: Altamente concentrado (i $>75 \%$ ), Alta Concentração $(65 \%<\mathrm{i}<75 \%)$, Concentração Moderada $(50 \%<\mathrm{i}<65 \%)$, Baixa Concentração $(35 \%<\mathrm{i}<50 \%)$, Ausência de Concentração $(\mathrm{i}<35 \%)$. Já, para o $\mathrm{CR}_{8}$, os mesmos níveis de mercado compreenderam os seguintes intervalos de valores: Altamente Concentrado (i $>90 \%)$, Alta Concentração $(85 \%<\mathrm{i}<90 \%)$, Concentração Moderada $(70 \%<\mathrm{i}<85 \%)$, Baixa Concentração $(45 \%<\mathrm{i}<70 \%)$ e Ausência de Concentração $(i<45 \%)$.

\section{Índice de Herfindahl-Hirschman (HHI)}

O índice de Herfindahl-Hirschman é uma medida estatística de concentração, sendo obtido através da soma dos quadrados das participações de cada nação no mercado internacional de celulose (NOCE et al., 2005). Portanto, considera a participação de todas as nações, aumentando o valor do índice à medida que a concentração é intensificada.

Kon (1994) explica que o índice Herfindahl-Hirschman (Equação 2) é um perfeito indicador da situação de mercado e é influenciado pelo número de participantes. Quando predomina apenas uma firma na indústria, o índice se iguala à unidade e quando as firmas têm participação igualitária, o índice assume seu valor inferior de $1 / \mathrm{n}$ ( $\mathrm{n}=$ número de firmas).

$$
H H I=\sum_{i=1}^{n} P i^{2}
$$

Em que: HHI = Índice de Herfindahl-Hirschman; Pi = Participação da empresa no total das exportações.

De acordo com Mendes (1998), se o valor de HHI, encontrado for inferior a 1000 o mercado é desconcentrado; para valores entre 1000 e 1800 é moderadamente concentrado; e para valores acima de 1800 o mercado é extremamente concentrado.

\section{Coeficiente de Gini}

O índice de Gini é uma medida de desigualdade muito utilizada para analisar a distribuição da renda, podendo ser utilizada para medir o grau de desigualdade de qualquer distribuição estatística sem nenhum inconveniente (HOFFMANN, 2006). Neste estudo, o índice de Gini (Equação 3) foi utilizado para medir o grau de desigualdade do mercado brasileiro, considerando o volume de celulose química exportada.

$$
G=1-\frac{\sum_{i=1}^{n}\left(C_{i j}+C_{i}\right)}{n}
$$

Em que: $\mathrm{G}$ = índice de Gini; $\mathrm{n}$ = número de nações; $\mathrm{Cij}$ = participação acumulativa nas exportações em ordem crescente; $\mathrm{Ci}=$ participação da nação i. 
Segundo Resende (1994), o índice de Gini assume valores entre zero e um, sendo que, $G=0$ significa ausência de concentração/igualdade absoluta entre todos os componentes do universo examinado e $\mathrm{G}=1$ significa que a concentração é absoluta ou o mercado está perante uma desigualdade total.

Para valores do índice de Gini, diferentes de 0 e de 1 , foi utilizada a classificação do grau de desigualdade proposta por Câmara (1949) com a seguinte interpretação: Nula a fraca $(0,101-0,250)$, Fraca a média $(0,251-0,500)$, Média a forte $(0,501-0,700)$, Forte a muito forte $(0,701-0,900)$ e, por último, Muito forte a absoluta $(0,901-1,000)$.

\section{RESULTADOS E DISCUSSÃO}

\section{Evolução das exportações brasileiras de celulose química}

As exportações brasileiras de celulose química ao longo do período analisado apresentaram aumento significativo de, aproximadamente, $450 \%$ e $818 \%$ em valor e volume, respectivamente. Esta diferença ocorreu porque os preços não acompanharam proporcionalmente o aumento do volume exportado. Em 1990, o montante exportado foi menor que US\$ 1 bilhão e em 2010, cerca de US\$ 4.5 bilhões. No primeiro ano, o volume exportado foi de pouco mais que 1,02 milhões de toneladas e no último ano consistiu em 8,37 milhões de toneladas.

No entanto, houve queda nas exportações, principalmente, em 2001, 2002 e 2009. Este fato está associado à supervalorização do real em 2002 (R\$ 3,50), à recessão americana de 2000 e 2001, assim como a crise mundial iniciada em 2008. Estas afirmações são sustentadas pela presidente da Bracelpa (ASSOCIAÇÃO BRASILEIRA DE CELULOSE E PAPEL, 2011), Elizabeth de Carvalhaes, em informativo da mesma instituição, em que afirmou que o impacto da valorização do Real e a retração do consumo mundial na crise foram negativos para as exportações deste produto.

O comportamento do preço unitário foi instável ao longo do período, não acompanhando o desempenho das curvas de valor e de volume, apesar de ser diretamente relacionado às duas variáveis. Assim, entre o primeiro e o último ano houve aumento de US\$ 0,85 , ou seja, $82 \%$. O teto foi alcançado em 2009 , quando o preço atingiu US\$2,63, seguindo as instabilidades financeiras em todo o mundo, e teve seu piso em 1995, quando decresceu para US\$ 0,94. Esta situação pode ser associada à maior oferta do produto, consequência do Segundo Programa Nacional de Papel e Celulose - II PNPC (MONTEBELLO, 2006).

O crescimento anual médio do valor exportado pelo Brasil foi de 6,57\%, enquanto o volume apresentou crescimento anual médio de $9,51 \%$. Essa diferença entre as taxas das duas variáveis é explicada pela flutuação do preço unitário, discutido acima.

\section{Principais parceiros}

Em 2010, o ranking dos principais países importadores de celulose química brasileira foi Países Baixos (20,2\%), Estados Unidos da América (20\%), China (19,9\%) e Itália (11,3\%). Estes se posicionaram entre os quatro primeiros desde 2003. Bélgica (6,9\%), Coreia do Sul (4,9\%), França (3,9\%) e Alemanha $(2,5 \%)$, respectivamente, completam a lista dos oito principais parceiros, tanto em 2009, quanto em 2010.

Os dados disponíveis referentes às exportações para os Países Baixos começam em 2003, com participação de $12,3 \%$ neste primeiro ano, atingindo 20,2\% em 2010. Durante o período analisado, os EUA ocupavam a primeira posição até 2008. Em 2010 participaram com 20\% do total, sendo que em 1990 esse valor era 12,36\% mais alto. O país que mais se destacou no estudo foi a China. De 1990 a 1995, sua participação nas exportações totais foi inferior a $2 \%$. Na Figura 1 pode-se constatar que houve crescimento nas comercializações entre os dois países, tendo assumido a primeira posição em 2009 , com $30,2 \%$ do total exportado pelo Brasil.

Por sua vez, a Itália quase triplicou sua participação, saindo de 4,1\% em 1990 e alcançando 11,3\% no último ano. Deve-se ressaltar que em 2010 o Brasil exportou volumes muito semelhantes para os três primeiros parceiros da lista. A Tabela 1 mostra o comportamento dos oitos principais importadores em porcentagem, assim como o valor total exportado pelo Brasil em cada ano em milhões de dólares. 
TABELA 1: Evolução da participação em valor dos principais países de destino de celulose brasileira (1990 - 2010). TABLE 1: Evolution of the participation of the major countries of destination of Brazilian pulp (1990 - 2010).

\begin{tabular}{ccccccccccc}
\hline & P. Baixos & China & EUA & Itália & Bélgica & $\begin{array}{c}\text { Coreia } \\
\text { do Sul }\end{array}$ & $\begin{array}{c}\text { França } \\
(\%)\end{array}$ & $\begin{array}{c}\text { Alemanha } \\
(\%)\end{array}$ & Outros & Total \\
& $(\%)$ & $(\%)$ & $(\%)$ & $(\%)$ & $(\%)$ & $(m i l h o ̃ e s)$ \\
\hline 1990 & N/C & 0,2 & 34,3 & 3,9 & 27,7 & 2,8 & 0,7 & 3,5 & 26,8 & 987,8 \\
1991 & N/C & 0,9 & 32,5 & 3,9 & 26,3 & 4,9 & 2,1 & 3,1 & 26,2 & 928,4 \\
1992 & N/C & 1,6 & 28,6 & 3,5 & 27,5 & 6,1 & 4,8 & 2,1 & 25,8 & 1142,8 \\
1993 & N/C & 1,1 & 26,3 & 3,0 & 21,4 & 6,1 & 4,7 & 2,0 & 35,4 & 1072,9 \\
1994 & N/C & 0,8 & 27,1 & 5,4 & 22,3 & 5,6 & 3,3 & 0,6 & 34,9 & 1235,5 \\
1995 & N/C & 0,3 & 30,0 & 5,0 & 24,1 & 4,8 & 4,8 & 0,03 & 31,0 & 2070,0 \\
1996 & N/C & 2,0 & 28,3 & 6,0 & 22,7 & 8,2 & 3,3 & N/C & 29,5 & 1326,3 \\
1997 & N/C & 3,6 & 25,4 & 5,8 & 16,4 & 5,6 & 3,8 & 3,4 & 35,9 & 1301,6 \\
1998 & N/C & 2,4 & 27,6 & 6,6 & 16,6 & 4,3 & 4,8 & 4,8 & 32,8 & 1327,8 \\
1999 & N/C & 4,4 & 27,4 & 6,4 & 15,0 & 5,2 & 5,0 & 5,6 & 30,9 & 1560,8 \\
2000 & N/C & 3,5 & 27,7 & 8,3 & 18,6 & 3,6 & 5,0 & 5,3 & 28,0 & 1947,5 \\
2001 & N/C & 10,2 & 28,1 & 7,3 & 14,3 & 3,0 & 4,8 & 4,4 & 27,9 & 1478,5 \\
2002 & N/C & 9,8 & 26,9 & 8,9 & 14,9 & 2,3 & 5,2 & 5,6 & 26,3 & 1349,6 \\
2003 & 13,8 & 15,3 & 25,6 & 8,2 & 8,2 & 2,7 & 3,2 & 1,0 & 21,9 & 2005,7 \\
2004 & 15,3 & 15,1 & 21,2 & 9,3 & 11,6 & 2,9 & 3,1 & 0,2 & 21,3 & 1925,0 \\
2005 & 19,7 & 11,6 & 20,3 & 9,4 & 9,5 & 2,6 & 2,8 & 1,2 & 22,8 & 2206,1 \\
2006 & 16,5 & 14,3 & 19,3 & 10,4 & 10,6 & 2,9 & 2,2 & 1,7 & 22,2 & 2626,8 \\
2007 & 19,3 & 13,1 & 20,6 & 11,5 & 10,3 & 2,4 & 2,9 & 1,3 & 18,5 & 3097,0 \\
2008 & 20,3 & 16,3 & 20,5 & 11,0 & 11,1 & 1,9 & 3,5 & 2,2 & 13,1 & 3822,0 \\
2009 & 14,8 & 29,0 & 16,7 & 9,6 & 8,9 & 3,9 & 3,6 & 3,0 & 10,4 & 3123,5 \\
2010 & 21,3 & 20,5 & 18,5 & 11,7 & 5,8 & 4,7 & 4,3 & 2,1 & 11,0 & 4434,2 \\
\hline
\end{tabular}

Fonte: Elaborado pelos autores. Dados: UnComtrade (2011).

\section{Razão de concentração (CR4)}

O país apresentou variação na concentração, com tendência à diminuição das concentrações entre 1990 e 2002, tendo saído do nível altamente concentrado e alcançado o de concentração moderada (Figura 1). 


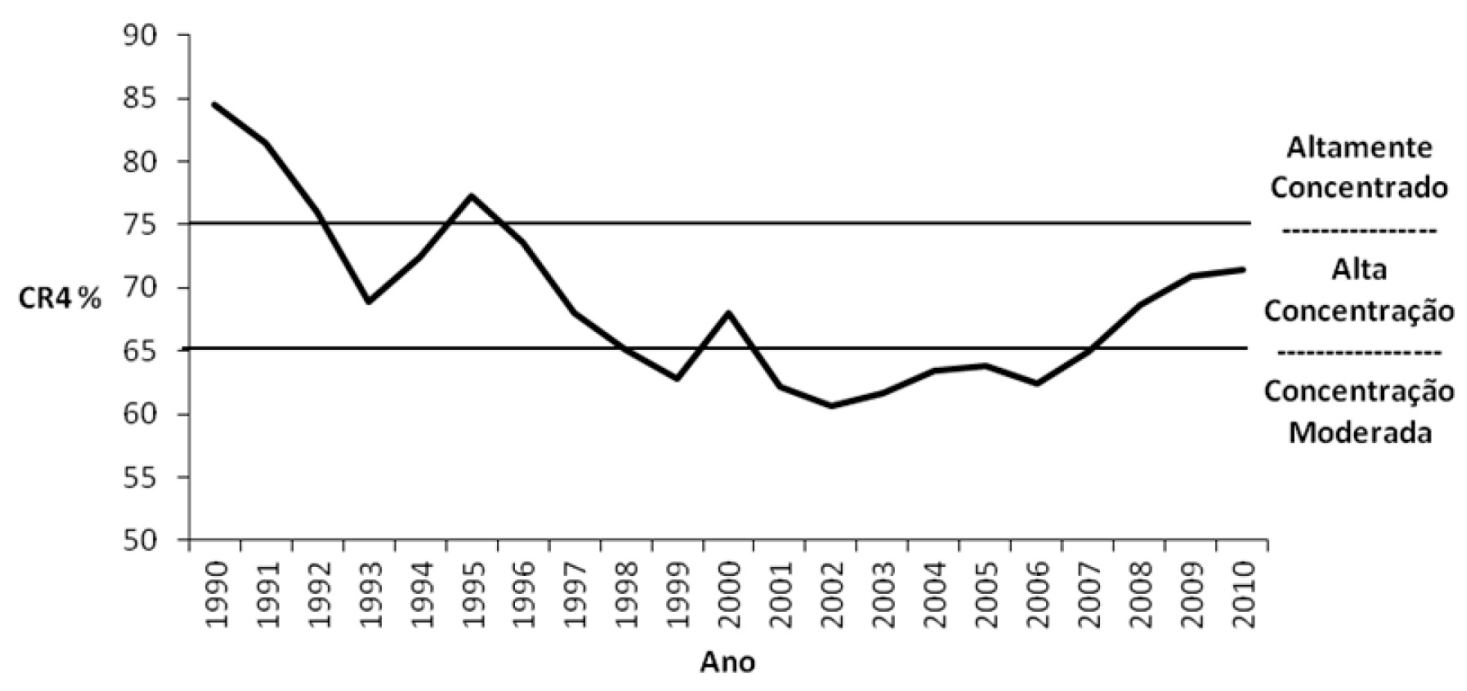

FIGURA 1: Evolução da razão de concentração (cr4) (1990 - 2010) (Fonte: Elaborado pelos autores. Dados: UnComtrade, 2011).

FIGURE 1: Evolution of the concentration ratio (cr4) (1990 - 2010).

Já em 1995, este índice apresentou pico de crescimento com CR4 igual a 77,2\% (Figura 1). O pico registrado neste ano pode ser explicado pelo Segundo Programa Nacional de Papel e Celulose - II PNPC, que tinha o objetivo de ampliar a oferta de celulose para aumentar as exportações (MONTEBELLO, 2006). Após o ano de 2002, a concentração voltou a crescer notavelmente até 2010, Alta Concentração, tendo saído de um índice de $60,6 \%$ para $71,5 \%$. Este fato ocorreu mesmo com a diminuição de parceiros comerciais na carteira de negócios.

Em 1990 havia 27 países para os quais o Brasil exportava esse produto, com CR4 igual a 84,5\%. Já em 2003, o país ampliou o número de compradores para um total de 49 países importadores da celulose química, reduzindo o CR4 para 61,7\%. Por sua vez, em 2010, o número de países importadores diminuiu para 40 e o índice de concentração CR4 voltou a ascender até $71.5 \%$.

\section{Razão de concentração (CR8)}

Foram ainda calculadas as razões de concentração para os oito principais parceiros (CR8) do Brasil neste mercado (Figura 2). A indústria de celulose, entre 1990 e 2001, partiu de um cenário altamente concentrado até a concentração moderada, tendo se elevado em 2002 para o nível de alta concentração e decrescido novamente em 2003 para a concentração moderada. A partir de 2004 voltou às características de alta concentração, quase atingindo o nível de altamente concentrado em 2010. Entre 1990 e 2010 houve queda de 6,4\% no nível do índice (Figura 2). 


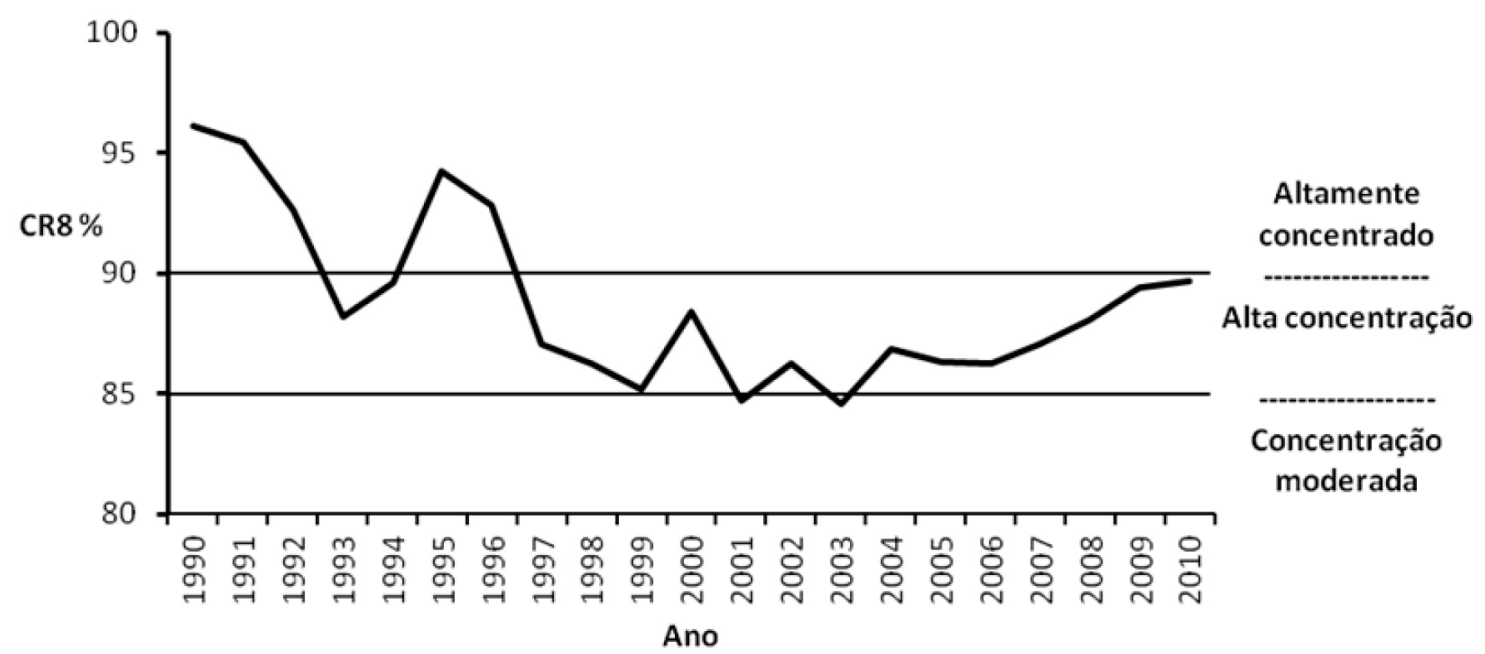

FIGURA 2: Evolução da razão de concentração (CR8) (1990 - 2010) (Fonte: Elaborado pelos autores. Dados: UnComtrade, 2011).

FIGURE 2: Evolution of the concentration ratio (CR8) $(1990-2010)$.

Ao se comparar com o ocorrido para o CR4, percebe-se que as concentrações diminuíram para os quatro principais importadores, mas se mantiveram relativamente estáveis entre os oito primeiros do ranking, no CR8.

As Figuras 1 e 2 mostram ainda que as duas séries temporais aparentam um comportamento similar pela forma como evoluíram no período estudado. De 1990 a 1993, houve diminuição da concentração dos quatro principais países (CR4), tendo saído do nível altamente concentrado $(84,5 \%)$, para concentração alta $(68,9 \%)$. O mesmo foi observado para os oito principais países (CR8) que saíram de uma participação de $96,1 \%$ para $88,2 \%$. Neste período, a distância entre o CR4 e o CR8 também aumentou saltando de $11,6 \%$ para 19,3\%. Porém, em 1995, a concentração voltou a aumentar tendo alcançado o nível de concentração muito alto, com uma participação de $77,2 \%$ para o CR4 e $94,2 \%$ para o CR8.

Já entre 1996 e 2006, as concentrações (CR4 e CR8) apresentaram variações com tendências decrescentes e aumento da distância entre os dois índices. Neste período, os quatro principais países diminuíram a participação no valor total exportado, saindo de $73,6 \%$, em alta concentração, para $62,5 \%$, alcançando concentração moderada. O mesmo ocorreu para os oito principais países (CR8), tendo saído de uma participação no valor total exportado de $92,8 \%$, nível altamente concentrado, para $86,3 \%$, alta concentração. Ainda entre 1996 e 2006 é possível notar que a distância entre o CR4 e o CR8 se ampliou, com uma variação de 19,2\%, em 1996, para 23,8\%, em 2006. Este fato revela que os oito principais países absorveram maior participação do valor total exportado quando comparado aos quatro principais.

\section{Índice de Hirschman-Herfindahl (HHI)}

O Índice de Hirschman-Herfindahl (HHI) posicionou-se em dois níveis de concentração: extremamente concentrado e moderadamente concentrado. Tal como aconteceu com o CR4 e o CR8, o valor de HHI mostrou desconcentração do mercado no início do período, tendo alcançado o nível moderadamente concentrado em 1993 e 1994, com valores de 1465 e 1676, respectivamente (Figura 3).

Um comportamento similar aos dos índices mencionados acima foi registrado em 1995, ao elevar o nível de concentração para extremamente concentrado, alcançado o valor de 1890,3. A partir de 1996, o valor de HHI voltou a decrescer tendo se mantido moderadamente concentrado durante o restante do período analisado, tendo o valor de 1222, o mais baixo da série, sido alcançado em 2006 (Figura 3). 


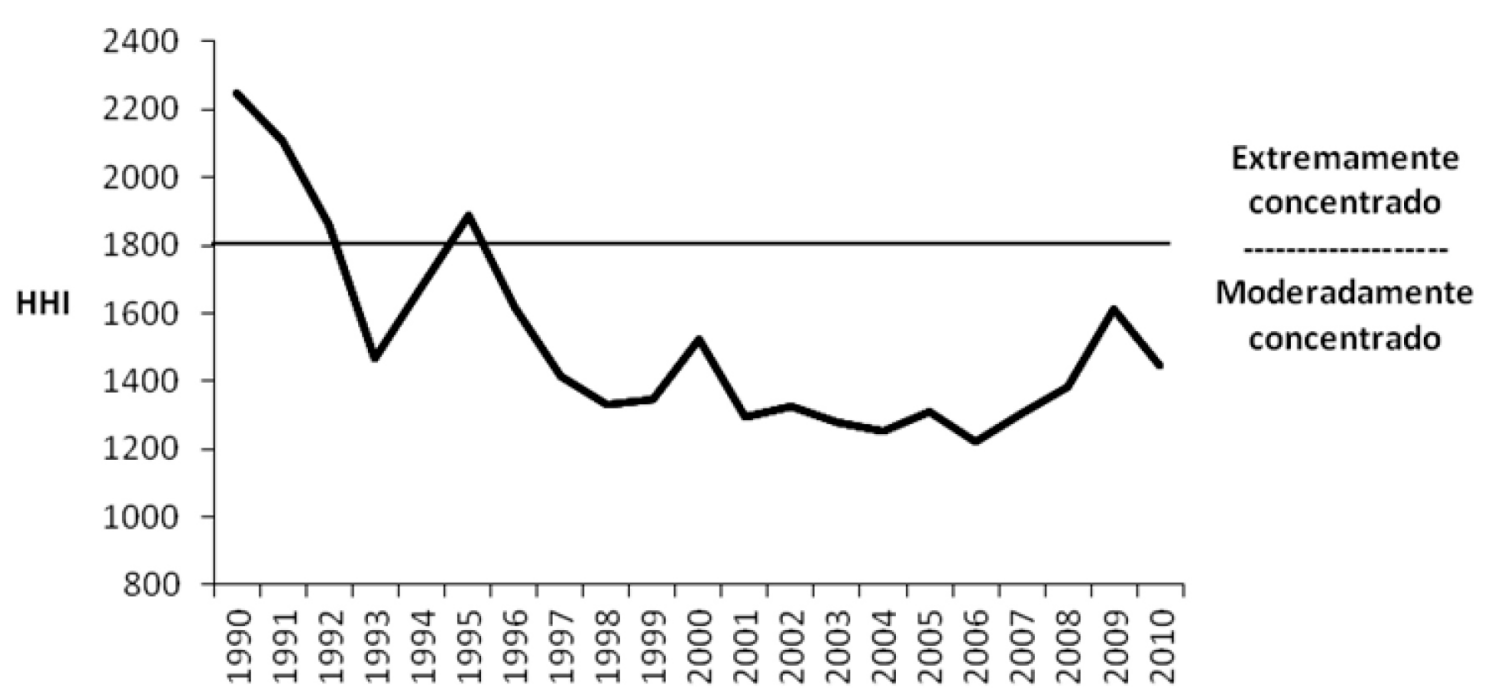

Ano

FIGURA 3: Índice de Hirschman-Herfindahl (HHI) (1990 - 2010). (Fonte: Elaborado pelos autores. Dados: UnComtrade, 2011).

FIGURE 3: Evolution of the Hirschman-Herfindahl Index (HHI) (1990 - 2010).

\section{Índice de Gini}

Os cálculos do Índice de Gini referentes às exportações da celulose química demonstraram a diminuição da desigualdade nas vendas no período de análise (Figura 4). Além do aumento do número de países parceiros, houve também maior distribuição do volume exportado entre estes clientes.

Com exceção do ano 1993 verificou-se uma desigualdade de muito forte a absoluta no período de 1990 a 1996 com valores de 0,921 e 0,909, respectivamente. No restante do período, os valores do índice de Gini oscilaram entre os níveis de desigualdade forte e muito forte. Finalmente, em 2000 e 2005 o índice calculado foi baixo, com valores de 0,844 e 0,848 .

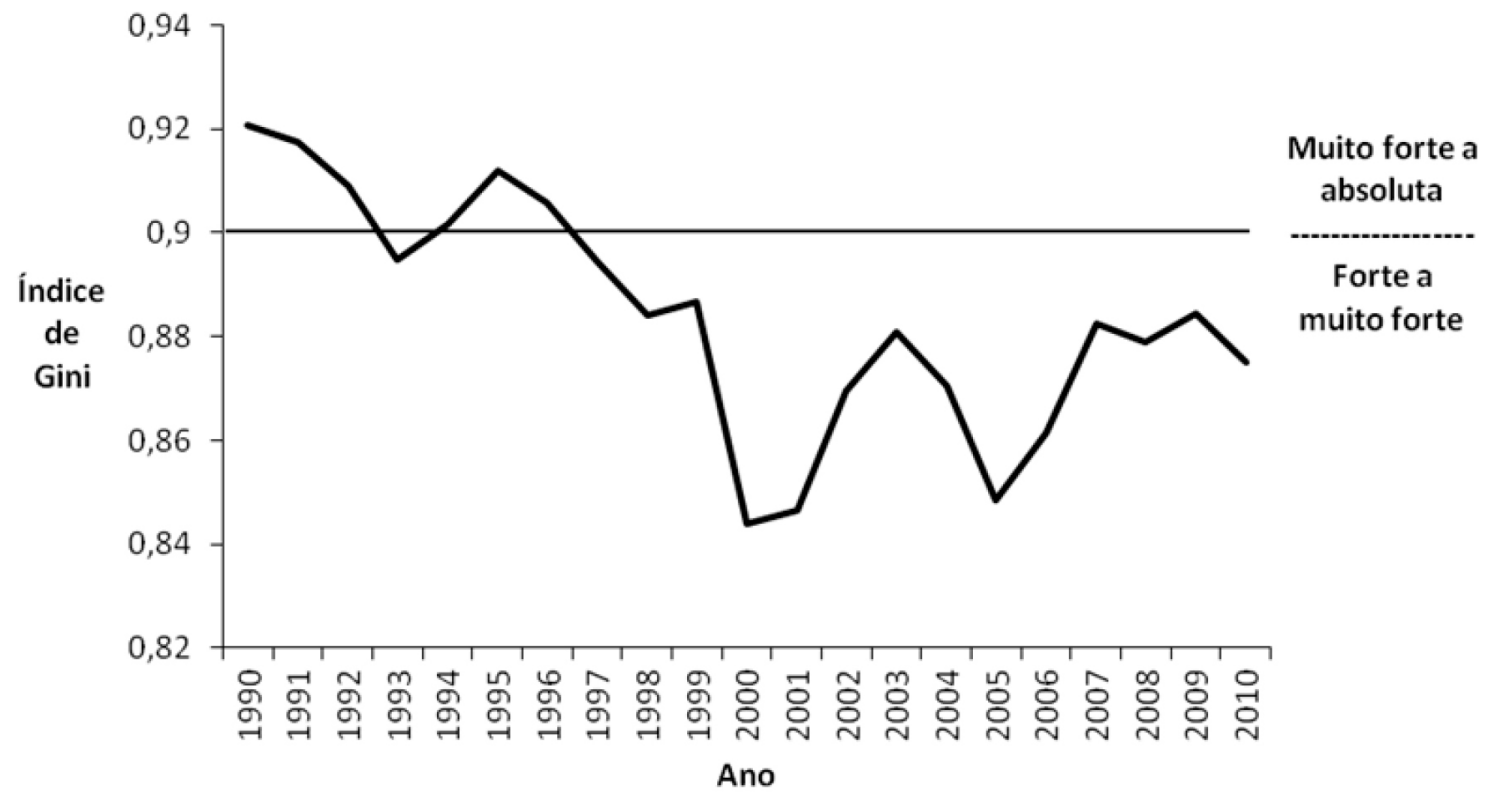

FIGURA 4: Evolução do Índice de Gini (1990 - 2010). (Fonte: Elaborado pelos autores. Dados: UnComtrade, 2011). FIGURE 4: Evolution of the Gini Index (1990 - 2010). 


\section{CONCLUSÕES}

Entre 1990 e 2010, as exportações brasileiras de celulose química tiveram um aumento de 4 vezes em termos de valor e 8 vezes em termos de volume. Seu preço, por sua vez, sofreu aumento de $82 \%$ no período. Os quatro principais parceiros comerciais do Brasil nesse mercado foram os Países Baixos, os Estados Unidos, a China e a Itália.

Ao final do período estudado, a concentração do mercado de celulose química brasileira foi considerada alta pelas análises CR4 e CR8. Já o Índice de Hirschman-Herfindahl considerou o mercado moderadamente concentrado na maior parte do período. Por fim, o índice de Gini demonstrou diminuição da desigualdade nas vendas do período, tendo havido aumento do número de países parceiros e maior distribuição do volume exportado entre eles.

Dessa forma, conclui-se que no período compreendido entre o ano de 1990 e 2010, o Brasil apresentou forte crescimento no valor real de exportação de celulose química com uma redução em sua concentração e desigualdade, diminuindo, por consequência, a dependência em relação a poucos parceiros comerciais.

\section{REFERÊNCIAS}

ASSOCIAÇÃO BRASILEIRA DE CELULOSE E PAPEL. [web site]. [2011]. Disponível em: <http:// www.bracelpa.org.br/bra2/index.php>. Acesso em: 15 mar. 2013.

CÂMARA, L. A. A concentração da propriedade agrária no Brasil. Boletim Geográfico, Rio de Janeiro, n. 77, p. 516-528, 1949.

CARVALHO, G. R. et al. Exportações mundiais de leite e derivados e analise da concentração entre 2002 e 2007. In: CONGRESSO DA SOCIEDADE BRASILEIRA DE ECONOMIA E SOCIOLOGIA RURAL, 47., 2009, Porto Alegre. Anais... Porto Alegre: [s. n.], 2009.

CAVES, R. E. American industry, structure, conduct and performance. Englewood Cliffs: Prentice Hall, 1982. 306 p.

COELHO JUNIOR, L. M. et al. Analysis of the Brazilian cellulose industry concentration (1998-2007). Cerne, Lavras, v. 16, n. 2, p. 209-216, 2010.

FEIJÓ, C. A.; CARVALHO, P. G. M.; RODRIGUES, M. S. Concentração industrial e produtividade do trabalho na indústria de transformação nos anos 90: evidências empíricas. Economia, Brasília, v.4, n. 1, p. 19-52, jan./jun. 2003.

HOFFMANN, R. Estatística para economistas. São Paulo: Biblioteca Pioneira de Ciências Sociais, 2006. $432 \mathrm{p}$.

KON, A. Economia industrial. São Paulo: Nobel, 1994. 212 p.

MARTINS, F. G.; ROCHA, C. H.; BARROS, A. P. Concentração na Indústria de transporte rodoviário interestadual e internacional de passageiros. In: CONGRESSO DA ANPET, 18., 2004, Florianópolis. Anais... Florianópolis: [s. n.], 2004. v. 2. p. 1373-1384.

MEDEIROS, N. H.; OSTROSKI, D. A. Competitividade e concentração de mercado: uma análise da avicultura nas mesorregiões Oeste e Sudoeste paranaense. In: CONGRESSO DA SOBER, 44., 2006, Fortaleza. Anais... Fortaleza: SOBER, 2006. p. 1-17.

MELVILLE, N.; GURBAXANI, V.; KRAEMER, K. The productivity impact of information technology across competitive regimes: The role of industry concentration and dynamism. Decision Support Systems, Irvine, v. 43, p. 229-242, 2007.

MENDES, J. T. G. Economia agrícola. Curitiba: ZNT, 1998. 458 p.

MONTEBELLO, A. E. S. Análise da Evolução da Indústria Brasileira de Celulose no Período de 1980 a 2005. 2006. 115 f. Dissertação (Mestrado em Economia Aplicada) - Escola Superior de Agricultura "Luiz de Queiroz", Universidade de São Paulo, Piracicaba, 2006.

NOCE, R. et al. Concentração das exportações no mercado internacional de madeira serrada. Revista Árvore, Viçosa, MG, v. 29, n. 3, p. 431-437, 2005.

NOCE, R. et al. Medida da desigualdade do mercado internacional de compensado. Cerne, Lavras, v. 13, n. 1, p. 107-110, 2007. 
RESENDE, M. Medida de concentração industrial: uma resenha. Análise Econômica, Porto Alegre, v. 11, p. 24-33, 1994.

SANTOS, M. A. S.; SANTANA, A. C. Concentração e poder de mercado das empresas de artefatos de madeira do Estado do Pará. In: ENCONTRO NACIONAL DE ENGENHARIA DE PRODUÇÃO, 23., 2003, Ouro Preto. Anais... Ouro Preto: [s. n.], 2003.

SILVA, Z. A. G. P. G. Análise econômica da concentração no uso de madeira tropical pelo setor de marcenarias de Rio Branco, Estado do Acre, 1996. Scientia Forestalis, Piracicaba, n. 64, p. 48-58, 2003.

SOARES, T. S. et al. Concentração no consumo de madeira e estrutura de mercado do setor moveleiro do município de Ubá/MG. Revista Científica Eletrônica de Engenharia Florestal, Garça, v. 4, n. 7, 2006. UNITED NATIONS COMMODITY TRADE STATISTICS DATABASE. UNComtrade. [2011]. Disponível em: $<$ http://comtrade.un.org/db/default.aspx>. Acesso em: mar. 2013. 